terms of the average of rheumatoid factor (RF) being higher in the group by CGE. On other hand, the group HV presented more consumption of complement, and showed the lowest average $p=0.0001$, without more severe clinical manifestations.

Table 1.

\begin{tabular}{|c|c|c|c|c|c|}
\hline & $R D(n=47)$ & $H V(n=91)$ & HD $(n=17)$ & CGE $(n=17)$ & \\
\hline Gender,n(\%) F & $42(89.4)$ & $57(62.6)$ & $7(41.2)$ & $11(64.7)$ & \\
\hline Age at dg, years, $( \pm S D)$ & $60.6( \pm 14)$ & $59.6( \pm 13.1)$ & $61.1( \pm 16.6)$ & $56.3( \pm 20.8)$ & $\mathrm{p}=0.8$ \\
\hline \multicolumn{6}{|c|}{ CLINICAL CHARACTERISTICS } \\
\hline Skin n (\%) & $18(38.3)$ & $10(11.0)$ & $2(11.8)$ & $9(52.9)$ & $p<0.001$ \\
\hline Raynaud n (\%) & $14(29.8)$ & & $1(5.9)$ & 3 (17.6) & $\mathrm{p}<0.001$ \\
\hline Purpura n (\%) & $6(12.8)$ & $9(9.9)$ & $2(11.8)$ & $6(35.3)$ & $p=0.04$ \\
\hline Acrocyanosis $\mathrm{n}(\%)$ & $6(12.8)$ & & & $1(5.9)$ & $\mathrm{p}=0.0033$ \\
\hline Ulcers n (\%) & $3(6.4)$ & $2(2.2)$ & - & $2(11.8)$ & $p=0.19$ \\
\hline Peripheric Neuro n (\%) & $10(21.3)$ & $9(9.9)$ & $1(5.9)$ & $4(23.5)$ & $p=0.13$ \\
\hline $\mathrm{N}-\mathrm{E}$ arthritis $\mathrm{n}(\%)$ & $22(46.8)$ & $8(8.8)$ & $1(5.9)$ & $4(23.5)$ & $p<0.001$ \\
\hline $\begin{array}{l}\text { GMN n (\%) } \\
\text { LABORATORY }\end{array}$ & $5(10.6)$ & $3(3.3)$ & $1(5.9)$ & $3(17.6)$ & $p=0.11$ \\
\hline $\mathrm{Cg}(\mathrm{mg} / \mathrm{dL}) \overline{\mathrm{x}}( \pm \mathrm{SD})$ & $26.7( \pm 63.2)$ & $65.8( \pm 256.5)$ & $\begin{array}{c}292.4 \\
( \pm 546.2)\end{array}$ & $47.59( \pm 79.1)$ & $p<0.001$ \\
\hline Isotype IgG, n (\%) & $\begin{array}{r}\mathrm{G}+\mathrm{M} 26 \\
(55.3)\end{array}$ & G+M $72(79.1)$ & M 8 (47.1) & $\begin{array}{r}G+M 12 \\
(70.6)\end{array}$ & \\
\hline ק2M ( $\geq 1.8$ mg/L), n (\%) & $7 / 40(17.5 \%)$ & $1 / 5(20.0 \%)$ & $3 / 12(25.0 \%)$ & - & $p=0.44$ \\
\hline $\mathrm{RCP}(\mathrm{mg} / \mathrm{L})$ p 50 & $10.3( \pm 26.2)$ & $3.9( \pm 3.0)$ & $13.4( \pm 18.3)$ & $8.5( \pm 12.0)$ & $p=0.47$ \\
\hline $\operatorname{ESR}(\mathrm{mm} / \mathrm{h}) \mathrm{p} 50$ & $40.0( \pm 28.5)$ & $20.3( \pm 20.2)$ & $35.4( \pm 35.1)$ & $24.5( \pm 25.0)$ & $\begin{array}{c}p= \\
0.0003\end{array}$ \\
\hline $\mathrm{RF}+(>20 \mathrm{Ul} / \mathrm{mL}), \mathrm{n}(\%)$ & 19/46 (41.3) & 44/86 (51.2) & $5 / 11(45.5)$ & $7 / 17(41.2)$ & $p=0.09$ \\
\hline p50 & $90.6( \pm 175.9)$ & $161.0( \pm 219.5)$ & $94.8( \pm 135.6)$ & $\begin{array}{l}284.5 \\
( \pm 619.3)\end{array}$ & $p<0.001$ \\
\hline C3 (<85mg/dL), n \%) & $20(42.6)$ & $47(51.6)$ & $3(17.6)$ & $3(17.6)$ & $p=0.13$ \\
\hline$\overline{\mathbf{x}}( \pm \mathrm{SD})$ & $90.1( \pm 28.6)$ & $68.5( \pm 10.8)$ & $99.1( \pm 29.0)$ & $114.8( \pm 12.7)$ & $p<0.001$ \\
\hline C4 (<12mg/dL), n (\%) & $17(36.2)$ & $36(39.6)$ & - & $3(17.6)$ & $p=0.02$ \\
\hline $\bar{x}( \pm S D)$ & $15.6( \pm 9.0)$ & $7.6( \pm 3.5)$ & $20.4( \pm 7.4)$ & $21.1( \pm 9.5)$ & $p<0.001$ \\
\hline
\end{tabular}

Conclusion: In our cohort, not all patients with CG presented clinical manifestations being those associated with CGE and RD those with the highest skin and joint expression. The most prevalent association of CG continues to be the HV and we confirmed the characteristic decrease in C3 and C4 complement levels, together with the positivity for RF.

Disclosure of Interests: None declared

DOI: 10.1136/annrheumdis-2021-eular.1758

\section{POS0828 $\quad$ CONSISTENT EFFICACY WITH APREMILAST IN MEN AND WOMEN TO TREAT ORAL ULCERS ASSOCIATED WITH BEHCCET'S SYNDROME: PHASE 3 RELIEF STUDY RESULTS}

G. Hatemi ${ }^{1}$, A. Mahr ${ }^{2}$, M. Takeno ${ }^{3}$, D. Kim ${ }^{4}$, M. Melikoglu' ${ }^{1}$, S. Cheng ${ }^{5}$, S. Richter ${ }^{5}$ S. Jardon ${ }^{5}$, M. Paris ${ }^{5}$, M. Chen ${ }^{5}$, Y. Yazici ${ }^{6} .{ }^{1}$ Istanbul University-Cerrahpassa, Cerrahpaşa Medical School and Behçet's Disease Research Center, Division of Rheumatology, Department of Internal Medicine, Istanbul, Turkey; ${ }^{2}$ Cantonal Hospital St. Gallen, Department of Rheumatology, St. Gallen, Switzerland; ${ }^{3}$ Nippon Medical School, Rheumatology, Kawasaki, Japan; ${ }^{4}$ Yonsei University College of Medicine and Severance Hospital, Department of Internal Medicine, Seoul, Korea, Rep. of (South Korea); ${ }^{5}$ Amgen Inc., Global Medical Affairs, Thousand Oaks, United States of America; ${ }^{6}$ New York University School of Medicine, Department of Medicine, New York, United States of America

Background: Painful, recurring oral ulcers (OU) associated with Behçet's syndrome negatively affect quality of life (QoL). Differences across sexes were reported in the frequency of disease manifestations, disease course, and response to colchicine. The phase 3, randomized, double-blind, placebo (PBO)-controlled RELIEF study showed overall efficacy of apremilast (APR) for OU associated with Behçet's syndrome, including improvements in OU pain, disease activity, and QoL.

Objectives: To evaluate the consistency of efficacy with APR in men and women with Behçet's syndrome.

Methods: Adults with active Behcet's syndrome and $\geq 3 \mathrm{OU}$ at randomization or $\geq 2 \mathrm{OU}$ at screening and randomization, without active major organ involvement, were randomized to APR $30 \mathrm{mg}$ BID or PBO during the 12-wk PBO-controlled phase. Randomization was stratified by sex. The primary endpoint was area under the curve for the number of $\mathrm{OU}$ through Wk $12\left(\mathrm{AUC}_{\mathrm{Wk} 0-12}\right)$ to assess continued efficacy over the time period in a symptom that waxed and waned. Key secondary endpoints included OU pain, complete response (OU-free), maintenance of complete response, and QoL at Wk 12. Disease activity was also assessed using Behçet's Syndrome Activity Score (BSAS) and Behçet's Disease
Current Activity Index Form (BDCAF). QoL was assessed using Behçet's Disease QoL (BDQoL). Prespecified subgroup analyses in men and women were performed to assess treatment effect in primary and secondary endpoints.

Results: Eighty men and 127 women were randomized and received $\geq 1$ dose of study medication. Mean age was $38.7 \mathrm{yrs}$ (men) and $40.8 \mathrm{yrs}$ (women). Mean (SD) OU count at baseline was 3.4 (1.4) (PBO) and 3.7 (1.5) (APR) for men and 4.3 (3.2) (PBO) and 4.5 (4.5) (APR) for women. Greater improvements in favor of APR vs PBO were observed in $\mathrm{AUC}_{W \mathrm{~W} 0-12}$ in men and women (Figure 1). Consistency in efficacy with APR was observed between men and women, with greater reduction in pain and achievement of OU complete response (OU-free) and maintenance of response at Wk 12 vs PBO (Table 1). In men and women, consistent treatment effects in favor of APR vs PBO were observed for disease activity and QoL measures, although moderate treatment differences were observed in BDCAI (men/women) and BDQoL (men) (Table 1).

Conclusion: Consistent treatment effects in favor of APR vs PBO in clinically relevant outcomes, including OU number and pain, OU complete response, and disease activity measures, were observed in men and women with $\mathrm{OU}$ associated with Behçet's syndrome.

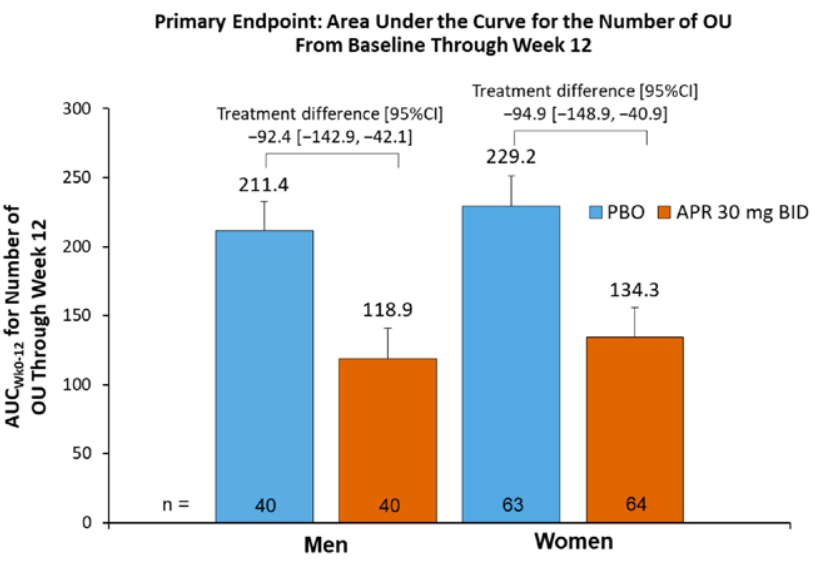

Intent-to-treat population. Error bars represent standard error. Multiple imputation used for imputing missing data.

\begin{tabular}{|c|c|c|c|c|c|c|}
\hline & \multicolumn{6}{|c|}{ Key Secondary Efficacy Outcomes at Wk 12} \\
\hline & \multicolumn{2}{|c|}{ Men } & \multicolumn{4}{|c|}{ Women } \\
\hline & $\begin{array}{c}\text { PBO } \\
(n=40)\end{array}$ & $\begin{array}{c}\text { APR } \\
(n=40)\end{array}$ & $\begin{array}{c}\text { Tx Difference } \\
{[95 \% \mathrm{Cl}]}\end{array}$ & $\begin{array}{c}\text { PBO } \\
(n=63)\end{array}$ & $\begin{array}{c}\text { APR } \\
(n=64)\end{array}$ & $\begin{array}{c}\text { Tx } \\
\text { Difference } \\
{[95 \% \mathrm{Cl}]}\end{array}$ \\
\hline OU CR, n/N (\%) & $\begin{array}{c}8 / 40 \\
(20.0)\end{array}$ & $\begin{array}{l}21 / 40 \\
(52.5)\end{array}$ & $\begin{array}{c}32.6 \\
{[12.8,52.4]}\end{array}$ & $\begin{array}{l}15 / 63 \\
(23.8)\end{array}$ & $\begin{array}{l}34 / 64 \\
(53.1)\end{array}$ & $\begin{array}{c}29.3 \\
{[13.2,45.4]}\end{array}$ \\
\hline $\begin{array}{l}\text { OU CR } 6+6^{*} \\
n / N(\%)\end{array}$ & $\begin{array}{l}1 / 40 \\
(2.5)\end{array}$ & $\begin{array}{l}10 / 40 \\
(25.0)\end{array}$ & $\begin{array}{c}22.8 \\
{[8.8,36.8]}\end{array}$ & $\begin{array}{l}4 / 63 \\
(6.3)\end{array}$ & $\begin{array}{l}21 / 64 \\
(32.8)\end{array}$ & $\begin{array}{c}26.5 \\
{[13.6,39.3]}\end{array}$ \\
\hline Pain (VAS)† & $\begin{array}{l}-12.0 \\
(4.8)\end{array}$ & $\begin{array}{l}-37.6 \\
(4.9)\end{array}$ & $\begin{array}{c}-25.6 \\
{[-37.2,-14.1]}\end{array}$ & $\begin{array}{l}-17.4 \\
(4.4)\end{array}$ & $\begin{array}{l}-41.5 \\
(4.3)\end{array}$ & $\begin{array}{c}-24.1 \\
{[-34.9,-13.3]}\end{array}$ \\
\hline BSAS† & $\begin{array}{l}-1.3 \\
(2.4)\end{array}$ & $\begin{array}{l}-14.4 \\
(2.4)\end{array}$ & $\begin{array}{c}-13.1 \\
{[-18.8,-7.3]}\end{array}$ & $\begin{array}{l}-7.7 \\
(2.4)\end{array}$ & $\begin{array}{l}-19.7 \\
(2.4)\end{array}$ & $\begin{array}{c}-12.0 \\
{[-18.0,-6.0]}\end{array}$ \\
\hline BDCAF† & & & & & & \\
\hline BDCAI & $\begin{array}{l}-0.1 \\
(0.3)\end{array}$ & $\begin{array}{l}-0.5 \\
(0.3)\end{array}$ & $\begin{array}{c}-0.4 \\
{[-1.1,0.4]}\end{array}$ & $\begin{array}{l}-0.7 \\
(0.3)\end{array}$ & $\begin{array}{l}-1.3 \\
(0.3)\end{array}$ & $\begin{array}{c}-0.6 \\
{[-1.2,0.0]}\end{array}$ \\
\hline $\begin{array}{l}\text { Patient's Perception of } \\
\text { Disease Activity }\end{array}$ & $\begin{array}{l}-0.2 \\
(0.3)\end{array}$ & $\begin{array}{l}-1.4 \\
(0.3)\end{array}$ & $\begin{array}{c}-1.2 \\
{[-1.9,-0.5]}\end{array}$ & $\begin{array}{l}-1.0 \\
(0.2)\end{array}$ & $\begin{array}{l}-1.8 \\
(0.2)\end{array}$ & $\begin{array}{c}-0.9 \\
{[-1.4,-0.3]}\end{array}$ \\
\hline $\begin{array}{l}\text { Clinician's Overall } \\
\text { Perception of } \\
\text { Disease Activity }\end{array}$ & $\begin{array}{l}-0.2 \\
(0.3)\end{array}$ & $\begin{array}{l}-1.5 \\
(0.3)\end{array}$ & $\begin{array}{c}-1.3 \\
{[-1.9,-0.7]}\end{array}$ & $\begin{array}{l}-1.0 \\
(0.2)\end{array}$ & $\begin{array}{l}-1.7 \\
(0.2)\end{array}$ & $\begin{array}{c}-0.7 \\
{[-1.3,-0.2]}\end{array}$ \\
\hline BDQoL $†$ & $\begin{array}{l}-0.7 \\
(1.0)\end{array}$ & $\begin{array}{l}-2.2 \\
(1.0)\end{array}$ & $\begin{array}{c}-1.5 \\
{[-3.8,0.8]}\end{array}$ & $\begin{array}{l}-0.3 \\
(0.9)\end{array}$ & $\begin{array}{l}-4.4 \\
(0.9)\end{array}$ & $\begin{array}{c}-4.1 \\
{[-6.3,-2.0]}\end{array}$ \\
\hline
\end{tabular}

LOCF analyses. *Proportion of patients achieving an $\mathrm{OU} \mathrm{CR}$ by $\mathrm{Wk} 6$, and remainin $\mathrm{OU}$-free for $\geq 6$ additional wks during the 12-wk PBO-controlled treatment phase. TLS mean (SE) change from baseline. BSAS = Behçet's Syndrome Activity Scores; BDCAF = Behçet's Disease Activity Form; $\mathrm{CR}=$ complete response; $\mathrm{n}=$ number of patients randomized to treatment; $T x=$ treatment

Acknowledgements: This study was funded by Celgene. Additional analyses were funded by Amgen Inc. Writing support was funded by Amgen Inc. and provided by Kristin Carlin, RPh, MBA, of Peloton Advantage, LLC, an OPEN Health company. 
Disclosure of Interests: Gulen Hatemi Speakers bureau: AbbVie, Novartis, and UCB, Grant/research support from: Celgene, Alfred Mahr Speakers bureau: Chugai and Roche, Consultant of: Celgene and Chugai, Mitsuhiro Takeno Speakers bureau: AbbVie, Esai, and Mitsubishi-Tanabe, Consultant of: Celgene, Grant/ research support from: Novartis, Doyoung Kim: None declared, Melike Melikoglu: None declared, Sue Cheng Employee of: Amgen Inc., Sven Richter Employee of: Amgen Inc., Shauna Jardon Employee of: Amgen Inc., Maria Paris Employee of: Amgen Inc., Mindy Chen Employee of: Amgen Inc., Yusuf Yazici Consultant of: Bristol-Myers Squibb, Celgene, Genentech, and Sanofi DOI: 10.1136/annrheumdis-2021-eular.1926

\section{\begin{tabular}{|l|l}
\hline POS0829 SPECIFICITY OF PANCA AUTOANTIBODIES IN &
\end{tabular} AUTOIMMUNE DISEASES}

O. Argyropoulou ${ }^{1}$, A. Tsirogianni ${ }^{2}$, C. Sfontouris ${ }^{3}$, G. Boutzios ${ }^{1}$, P. Vlachoyiannopoulos ${ }^{1}$, A. Tzioufas ${ }^{1}$, E. Kapsogeorgou ${ }^{1} .{ }^{1}$ School of Medicine, National and Kapodistrian University of Athens, Pathophysiology, Athens, Greece; ${ }^{2}$ Evangelismos General Hospital, Immunology and Histocompatibility, Athens, Greece; ${ }^{3}$ Evangelismos General Hospital, Rheumatology, Athens, Greece

Background: The clinical significance of pANCA by indirect immunofluorescence is well-established. However, their clinical utility is sometimes hindered by the fact that pANCA are also detected in various autoimmune diseases. Myeloperoxidase (MPO) is considered as the major autoantigen recognized by pANCA in ANCA-associated vasculitides (AAV) and predominantly in microscopic polyangiitis (MPA). However, information regarding the targets of PANCA in other autoimmune diseases is still elusive.

Objectives: To investigate the specific autoantigens recognized by pANCA in autoimmune diseases.

Methods: Sera from all patients that were found positive for pANCA in the diagnostic laboratories of the Department of Pathophysiology, School of Medicine, National and Kapodistrian University of Athens and the Department of Immunology and Histocompatibility, Evangelismos General Hospital, Athens, Greece during the last two years were studied. The pANCA+ sera were evaluated for reactivity with the major antigens that are recognized by pANCA [MPO, lactoferrin, neutrophil elastase, cathepsin $\mathrm{G}$ and bactericidal/permeability increasing protein (BPI)] by a commercially available multiplex ELISA (ANCA profile ELISA, Euroimmun, Lubeck, Germany).

Results: A total of 82 patients were included in the study. All patients had positive pANCA by indirect immunofluorescence with a title ranging from $1 / 160$ to $1 / 640$. According to respective classification criteria, 21 patients had systemic vasculitides (15 MPA, 1 granulomatosis with polyangiitis; GPA, 1 Behcet's disease; BD, 1 aortitis, 2 Henoch-Schonlein purpura; HSP and 1 cryoglobulinemic vasculitis; CV), 29 had systemic lupus erythematosus (SLE), 6 antiphospholipid syndrome (APS), 8 Sjögren's syndrome (SS), 2 rheumatoid arthritis (RA), 1 systemic scleroderma (SScl), 14 Hashimoto thyroiditis and 1 sarcoidosis. The specificities of pANCA in each entity are shown in the following table.

\begin{tabular}{|c|c|c|c|c|c|c|}
\hline \multirow{2}{*}{$\begin{array}{l}\text { Autoimmune } \\
\text { Diseases }\end{array}$} & & \multicolumn{5}{|c|}{ Antigens recognized by pANCA+ sera } \\
\hline & & MPO & Elastase & Cathepsin G & BPI & Lactoferrin \\
\hline \multirow[t]{6}{*}{ Vasculitides } & MPA & $66.7(10 / 15)$ & $0(0 / 15)$ & $0(0 / 15)$ & $0(0 / 15)$ & $0(0 / 15)$ \\
\hline & GPA & $100(1 / 1)$ & $0(0 / 1)$ & $0(0 / 1)$ & $0(0 / 1)$ & $0(0 / 1)$ \\
\hline & $\mathrm{BD}$ & $100(1 / 1)$ & $0(0 / 1)$ & $0(0 / 1)$ & $0(0 / 1)$ & $0(0 / 1)$ \\
\hline & Aortitis & $0(0 / 1)$ & $0(0 / 1)$ & $0(0 / 1)$ & $0(0 / 1)$ & $0(0 / 1)$ \\
\hline & HSP & $0(0 / 2)$ & $0(0 / 2)$ & $0(0 / 2)$ & $0(0 / 2)$ & $0(0 / 2)$ \\
\hline & CV & $0(0 / 1)$ & $0(0 / 1)$ & $0(0 / 1)$ & $0(0 / 1)$ & $100(1 / 1)$ \\
\hline SLE & & 6.9 (2/29) & $0(0 / 29)$ & $0(0 / 29)$ & $0(0 / 29)$ & 6.9 (2/29) \\
\hline APS & & $16.6(1 / 6)$ & $16.6(1 / 6)$ & $0(0 / 6)$ & $0(0 / 6)$ & $0(0 / 6)$ \\
\hline SS & & $0(0 / 8)$ & $12.5(1 / 8)$ & $0(0 / 8)$ & $12.5(1 / 8)$ & $0(0 / 8)$ \\
\hline RA & & $50(1 / 2)$ & $0(0 / 2)$ & $0(0 / 2)$ & $0(0 / 2)$ & $0(0 / 2)$ \\
\hline SScl & & $100(1 / 1)$ & $0(0 / 1)$ & $0(0 / 1)$ & $0(0 / 1)$ & $0(0 / 1)$ \\
\hline Hashimoto & & $0(0 / 14)$ & $0(0 / 14)$ & $0(0 / 14)$ & $0(0 / 14)$ & $0(0 / 14)$ \\
\hline Sarcoidosis & & $0(0 / 1)$ & $0(0 / 1)$ & $0(0 / 1)$ & $0(0 / 1)$ & $0(0 / 1)$ \\
\hline
\end{tabular}

Conclusion: pANCA positive staining in AAVs is highly restricted to MPO specificity. On the contrary, pANCA staining pattern in other autoimmune diseases, involves unknown autoantigens that are under investigation in our laboratory.
Disclosure of Interests: None declared

DOI: 10.1136/annrheumdis-2021-eular.1949

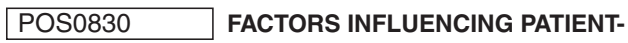 REPORTED OUTCOMES IN ANCA-ASSOCIATED VASCULITIS}

S. Monti ${ }^{1,2}$, P. Delvino ${ }^{1,2}$, C. Klersy ${ }^{3}$, G. Coppa ${ }^{4}$, A. Milanesi $^{1}$, C. Montecucco ${ }^{1}$ ${ }^{1}$ Pavia, Rheumatology, IRCCS Policlinico S. Matteo Fondazione, Pavia, Italy; ${ }^{2}$ Pavia, PhD in Experimental Medicine, University of Pavia, Pavia, Italy; ${ }^{3}$ Pavia, Biometry and Clinical Epidemiology, IRCCS Policlinico S. Matteo Fondazione, Pavia, Italy; ${ }^{4}$ Pavia, University of Pavia, School of Medicine and Surgery, Pavia, Italy

Background: Patient-reported outcomes (PROs) are currently poorly integrated in the clinical evaluation of disease activity in patients with ANCA-associated vasculitis (AAV).

Objectives: To assess the distribution of the Patient Global Assessment (PtGA) in patients with $A A V$ in stable remission, and to identify correlates of PtGA; to assess the discordance between PtGA score and PhGA.

Methods: Patients with a diagnosis of AAV [eosinophilic granulomatosis with polyangiitis, granulomatosis with polyangiitis, microscopic polyangiitis] in stable, complete remission (defined by a BVAS $=0$ ) and with a Physician Global Assessment $(P h G A)=0$ were included. A questionnaire including several aspects of disease captured by PROs was collected. PtGA on a 0-100 mm visual analogue scale (VAS) was assessed, with higher scores representing higher/worse levels of disease activity. Similarly, VAS for pain, chronic damage according to the patient's opinion, general health $(\mathrm{GH})$, fatigue, and sleep quality were collected. The worst symptom in the patient's opinion affecting the overall assessment of disease activity was recorded. The Cragg Hurdle model was used to assess the predictors of PtGA.

Results: 65 patients were included, female $57 \%$, mean age $61 \pm 12$ years Mean disease duration at enrollment was $8 \pm 6$ years. Mean vasculitis damage index (VDI) was $4.4 \pm 2.3$, with $45 \%$ of patients having a VDI $\geq 5$. Despite having been classified as being in remission, PtGA was elevated in $37 \%$ of patients. We explored several correlates of PtGA. Higher degree of damage accrual (VDI) did not influence the patient's evaluation of current disease activity. Similarly, we did not identify a correlation between older age, educational level, number of organ-systems involved, number of comorbidities, the number of previous major or minor relapses, higher disease duration, nor the type of AAV diagnosis (figure 1, panel A). Only sex significantly correlated with PtGA scores: $19(51 \%)$ of female patients reported an elevated PtGA compared to only $5(18 \%)$ of male $(p=0.009)$. PtGA resulted to be significantly correlated with other (mostly modifiable) PROs including VAS pain, perception of the level of chronic damage accrual, $\mathrm{GH}$, and fatigue (figure 1, panel B). The agreement between patients' and physicians' assessments of disease activity was $63 \%$. Patients reported pain, followed by chronic respiratory symptoms to be the worst-experienced ongoing manifestations affecting their evaluation of disease activity.

Conclusion: A significant proportion of patients with AAV considered to be in remission by the physician still declares to have persistent aspects of uncontrolled disease. PtGA is significantly influenced by persistent pain and fatigue which warrant better assessment in the future.
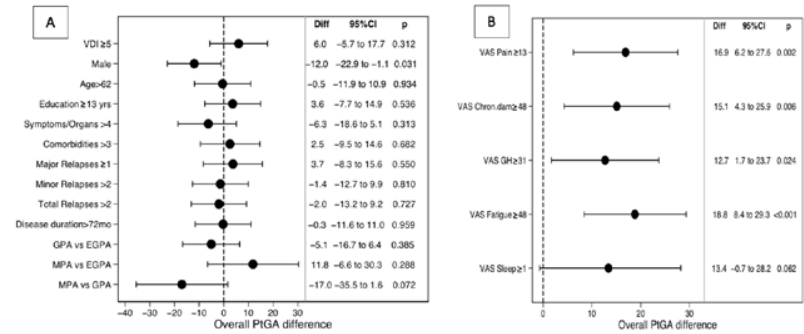

Figure 1. Forrest plots of correlates of the Patient Global Assessment (PtGA): patient- and disease-related items (Pan A); influence of other patient-reported outcomes (Panel B). Cut-off values were identified based on the median value of the population. 